\title{
Glycemic Index of Selected Newly Released Rice Varieties of Northern Telangana Region, India
}

\author{
R. Anitha ${ }^{1}$, K. Manorama ${ }^{2}$, W. Jessi Sunitha ${ }^{1}$ and M. Sreedhar ${ }^{2}$ \\ ${ }^{1}$ Post Graduate \& Research Centre, ${ }^{2}$ Quality Control Laboratory, Professor Jayashankar \\ Telangana State Agricultural University, Hyderabad \\ *Corresponding author
}

\begin{tabular}{|c|c|}
\hline \multicolumn{2}{|r|}{ A B S T R A C T } \\
\hline & \multirow{6}{*}{$\begin{array}{l}\text { Glycemic index (GI) is an important parameter of food quality which compares the } \\
\text { hyperglycemic effect of a tested meal with pure glucose. Glycemic index of different } \\
\text { varieties of rice (Oryza sativa) such as Pradhyumna (JGL-17004) and Anjana (JGL-11118) } \\
\text { were determined. Clinically healthy adult subjects (n=20) of age } 19-25 \text { years were } \\
\text { selected for the determination of glycemic index of the rice varieties Anjana (JGL-11118) } \\
\text { and Pradhyumna (JGL-17004). The mean fasting blood glucose level of the participants } \\
\text { was } 88.9 \pm 12.1 \mathrm{mg} / \mathrm{dl} \text {. The mean blood glucose level at } 30 \text { min and } 60 \text { min after the oral } \\
\text { administration of } 64 \mathrm{~g} \text { of glucose were } 159 \pm 25.5 \text { and } 125 \pm 30.8 \text {. Different varieties of } \\
\text { cooked rice (Anjana (JGL-11118) and Pradhyumna (JGL-17004) containing } 64 \mathrm{~g} \\
\text { digestible carbohydrate were administered to the participants, and the peak blood glucose } \\
\text { response was obtained at } 30 \text { min. The mean glycemic response of Anjana (JGL-11118) } \\
\text { and Pradhyumna (JGL-17004) at } 30 \text { min ranged between } 131 \pm 21.3 \text { and 127.6 } \pm 17.2 \text {. } \\
\text { Results had shown that GI values for Anjana (JGL-11118) was } 52.7 \text { and for Pradhyumna } \\
\text { (JGL-17004) rice variety, GI value was } 51.3 \text {. These differences were non significant and } \\
\text { varieties were categorised as low glycemic index rice varieties. }\end{array}$} \\
\hline Keywords & \\
\hline $\begin{array}{l}\text { Rice, Glycemic } \\
\text { index. }\end{array}$ & \\
\hline Article Info & \\
\hline $\begin{array}{l}\text { Accepted: } \\
\text { 29 June } 2017 \\
\text { Available Online: } \\
\text { 10 July } 2017\end{array}$ & \\
\hline & \\
\hline
\end{tabular}

\section{Introduction}

Rice is a staple food consumed by more than half of the world population (FAOSTAT, 2014). It provides 20 percent of the world's dietary energy supply, while wheat supplies 19 percent and maize 5 percent (FAO, 2004). It is the predominant dietary energy source for 17 countries in Asia and the Pacific and 9 countries in North and South Africa.

In 59 countries, an average of at least $75 \mathrm{~g}$ of rice is available per person per day (FAOSTAT, 2014). The total population of these countries is 4.1 billion which indicates that reaching even half of that population would ensure a greater daily nutrient intake among 2 billion people (FFI, 2014). Rice has always played a very important role in the food grain category and it is also very necessary for the production of other products for which rice is used as a raw material. Production of Rice in 1950-51 was 20.58 million tonnes; in 1960-61 it was 34.58 million tonnes which later increased very rapidly with the production of 42.22 million tonnes in 1970-71 and 53.63 million tonnes in 1980-81. In the decades of 90's, production increased to 74.29 million tonnes and in 2000-01 it increased up to 84.98 million 
tonnes. 2010-11 data shows the surplus of 95.98 million tonnes production and 2012-13 (4th advance estimation) data shows that production of rice increased up to 104.40 million tonnes, India being the second largest producer of rice in the world (Vijay, 2015). The slogan 'Rice is Life' is more appropriate for India as this crop plays a vital role in our National food security and is a means of livelihood for millions of rural households (Uma et al., 2012). Considering the importance of the rice, the United Nations Food and Agricultural organization has declared the year 2004 as the "International Year of Rice". Global production of paddy is increasing year after year which could be primarily due to India whose production is predicted to increase by $18 \%$.

Starch is the most common carbohydrate in rice. The basic components of rice starch are amylose and amylopectin. Variation in the glycemic index of rice is due to differences in the proportion of amylose and amylopectin content of starch. Higher the amylose content, lower the glycemic index, hence amylose rich starch is a potential benefit to carbohydrate sensitive or diabetic individuals. However, the general public, especially diabetics have a notion that rice should be avoided, as it's glycemic index value is high. However, it was reported that rice contains $20 \%$ amylose which has been shown to have a slower rate of digestion and produces lower glycemic and insulin responses (Miller et al., 1992).

Despite numerous studies on different varieties of rice, there is lack of published data on glycemic index of newly released rice varieties of Telangana. Low glycemic index rice varieties with good nutritional composition may encourage farmers as well as consumers for increasing their demand. Hence, the present study was undertaken to determine glycemic index profile of the selected newly released rice varieties of Northern telangana region.

\section{Materials and Methodology}

\section{Materials}

One of the new released rice varieties viz Anjana (JGL-11118) and Pradhyumna (JGL17004) were procured from Regional Agricultural Research Station, Jagityal, Karimnagar.

\section{Experimental design}

Clinically healthy adult subjects $(n=20)$ of age 19 - 25 years were selected for the study of glycemic index of the rice varieties, JGL11118 and JGL-17004. After an overnight fast, blood glucose was checked for fasting level and then the subjects were fed $50 \mathrm{~g}$ of Glucon-D as a reference food and blood glucose was checked at 15, 30, 45, 60, 90 and 120 minutes according to the method of Wolever et al., (1991).

The subjects were allowed a normal diet for next three days and then again after an overnight fast, the fasting blood glucose level was taken and then the subjects were fed with $50 \mathrm{~g}$ of carbohydrate equaled test food (cooked plain rice). Subjects were given 10 mins to complete the given test food portion with drinking water $(250 \mathrm{ml})$ and asked to chew the food thoroughly and then blood glucose was checked at 15, 30, 45, 60, 90 and 120 minutes.

\section{Blood sampling and analysis}

Capillary blood was taken from finger tips for blood glucose estimation using Glucometer (One Touch). The blood samples were taken at fasting state (0 min) and at 15, 30, 45, 60, 90 and 120 min interval after ingestion of the reference food as well as test food. The subjects were restricted from performing any physical activity during the $2 \mathrm{hr}$ of study period. The area under curve (AUC) of GI of 
rice was calculated for each subject. The Incremental Area Under Curve (IAUC) of both reference and test food was used to obtain the Glycemic Index (GI) by the following formula:

\section{$G_{\text {food }}=\frac{\text { IAUC in response to a relevent test food portion }}{\text { IAUC in response to equal weight of reference food (Glucose) }}$ $X$ Amount of food (100)}

\section{Statistical analysis}

Data were expressed as mean \pm standard deviation, comparison of the glycemic response of different of varieties of rice with glycemic response of glucose were made by paired t-test.

\section{Results and Discussion}

The Glycemic index of two newly released rice (Oryza sativa) varieties such as Anjana (JGL-11118) and Pradhyumna (JGL-17004) were determined. Clinically healthy adult subjects $(n=20)$ of age 19 - 25 years were selected for the study of glycemic index of the rice varieties Anjana (JGL-11118) and Pradhyumna (JGL-17004) (Figs. 1 and 2).

Table.1 Mean blood glucose response to reference and test food (in $\mathrm{mg} / \mathrm{dl}$ )

\begin{tabular}{|l|c|c|c|}
\hline \multicolumn{1}{|c|}{ Time Interval } & $\begin{array}{c}\text { Blood Glucose Response to } \\
\text { Reference Food(Glucose) } \\
(\mathbf{n = 2 0})\end{array}$ & $\begin{array}{c}\text { Blood Glucose Response } \\
\text { to Test Food (JGL-11118 } \\
\text { Rice) }(\mathbf{n = 2 0})\end{array}$ & \multirow{2}{*}{ P value } \\
\hline $0 \mathrm{~min}$ (Fasting) & $88.9 \pm 12.1$ & $80.89 \pm 7.1$ & \multirow{2}{*}{$0.013343^{\mathrm{SD}}$} \\
\hline $15 \mathrm{~min}$ & $126.7 \pm 23.3$ & $125.1 \pm 21.7$ & \\
\hline $30 \mathrm{~min}$ & $159 \pm 25.5$ & $131.1 \pm 21.3$ & \\
\hline $45 \mathrm{~min}$ & $153.1 \pm 55.9$ & $111.2 \pm 18.6$ & \\
\hline $60 \mathrm{~min}$ & $125.6 \pm 28.2$ & $102.7 \pm 15.4$ & \\
\hline $90 \mathrm{~min}$ & $106.8 \pm 17.8$ & $98.3 \pm 14.0$ & \\
\hline $120 \mathrm{~min}$ & $98.6 \pm 20.1$ & $94.4 \pm 10.9$ & \\
\hline
\end{tabular}

${ }^{*}$ Significance Level-P-value-P $<0.050 .013343^{\mathrm{SD}}$ significant difference

Table.2 Mean blood glucose response to reference and test food (in $\mathrm{mg} / \mathrm{dl}$ )

\begin{tabular}{|l|c|c|c|}
\hline \multicolumn{1}{|c|}{ Time Interval } & $\begin{array}{c}\text { Blood Glucose Response to } \\
\text { Reference Food (Glucose) } \\
(\mathbf{n = 2 0})\end{array}$ & $\begin{array}{c}\text { Blood Glucose Response } \\
\text { to Test Food (JGL-17004 } \\
\text { Rice) }(\mathbf{n = 2 0})\end{array}$ & \multirow{2}{*}{ P value } \\
\hline $0 \mathrm{~min}($ Fasting) & $88.9 \pm 12.1$ & $83.1 \pm 5.0$ & \multirow{2}{*}{$0.013887^{\mathrm{SD}}$} \\
\hline $15 \mathrm{~min}$ & $126.7 \pm 23.3$ & $127.6 \pm 16.9$ & \\
\hline $30 \mathrm{~min}$ & $159 \pm 25.5$ & $127.6 \pm 17.2$ & \\
\hline $45 \mathrm{~min}$ & $153.1 \pm 55.9$ & $116.9 \pm 23.5$ & \\
\hline $60 \mathrm{~min}$ & $125.6 \pm 28.2$ & $108.3 \pm 21.1$ & \\
\hline $90 \mathrm{~min}$ & $106.8 \pm 17.8$ & $94.7 \pm 16.0$ & \\
\hline $120 \mathrm{~min}$ & $98.6 \pm 20.1$ & $93.6 \pm 13.4$ & \\
\hline
\end{tabular}

$*$ Significance Level-P-value-P $<0.050 .013343^{\mathrm{SD}}$ significant difference 
Fig.1 Mean blood glucose response to reference and test food (in $\mathrm{mg} / \mathrm{dl}$ )

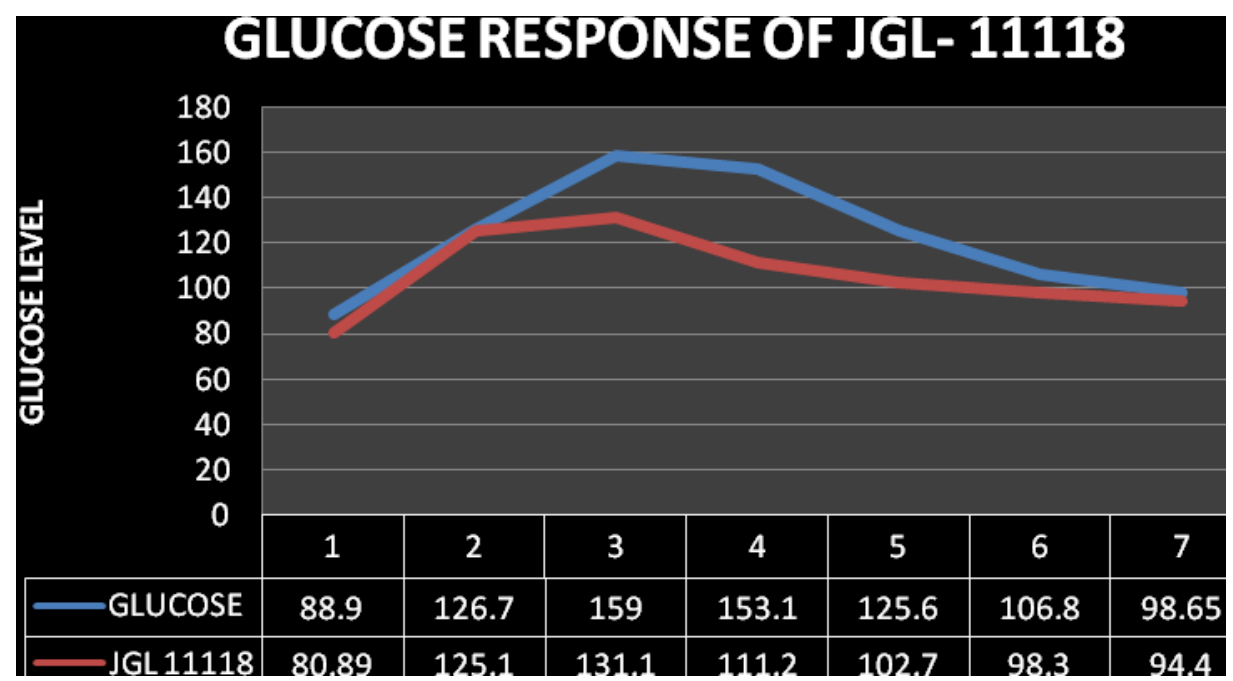

Fig.2 Mean blood glucose response to reference and test food (in mg/dl)

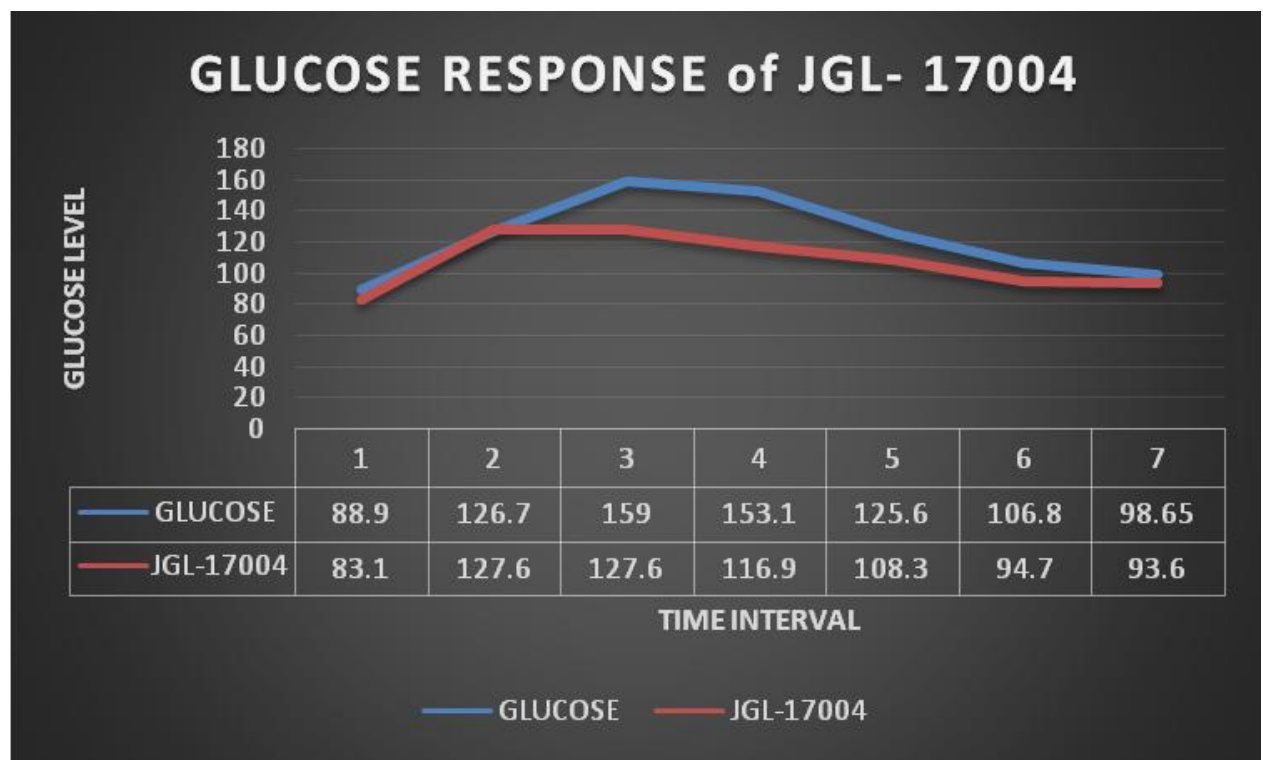

The blood samples were taken at fasting state (0 min) and at 15, 30, 45, 60, 90, and $120 \mathrm{~min}$ interval after ingestion of the reference food and test food. According to Jenkins et al., (1981) Glycemic Index (GI) can be defined as the incremental area under blood glucose response curve of a $50 \mathrm{~g}$ carbohydrate dose from a reference food (white bread or glucose) taken by the same subject over a specified period of time. For determining glycemic index, foods are categorised as low
(GI value < 55), medium (GI value 56-69) or high GI foods (> 70).

The mean fasting blood glucose level of the participants was $88.9 \pm 12.1 \mathrm{mg} / \mathrm{dl}$, and the mean blood glucose level at $30 \mathrm{~min}$ and 60 min after the oral administration of $64 \mathrm{~g}$ of glucose were $159 \pm 25.5$ and $125 \pm 30.8$. Different varieties of cooked rice (Anjana (JGL-11118) and Pradhyumna (JGL-17004) containing $64 \mathrm{~g}$ digestible carbohydrate were 
administered to the participants, and the peak blood glucose response was obtained at 30 min. Results of glycemic response of Anjana (JGL-11118) and Pradhyumna (JGL-17004) rice varieties with pure Glucose are summerized in the tables 1 and 2 . The results indicated that when new released rice variety Anjana (JGL-11118) was orally administered to the selected subjects the test food had a maximum peak levels that is $131 \pm 21.3$ at 30 minute, therefore, from the present study, it was observed that reference food (glucose) had a maximum peak level $(159 \pm 25.5)$ compared to the test foods (JGL-11118). When Pradhyumna (JGL-17004) rice was orally administered to the selected subjects, it showed a maximum peak level of $127.6 \mathrm{mg} / \mathrm{dl}$ at $30 \mathrm{~min}$ and reference food (glucose) showed a maximum peak level of $159 \mathrm{mg} / \mathrm{dl}$ at the same time. Shobana, et al., (2012) reported GI values for Sona Masuri (72.0 \pm 4.5), Ponni (70.2 \pm 3.6$)$ and Surti Kolam (77.0 \pm 4.0 ) rice varieties were non-significant and all were classified as high GI varieties of rice.

Results revealed that there was a significant difference $(p<0.050)$ between test foods (JGL-11118, JGL-17004) in comparison with reference food (Glucose), but there was no significant difference between the test foods. After estimation, the Glycemic Index value of Pradhyumna (JGL-17004) and Anjana (JGL11118) varieties of rice was established to be 51.3 and 52.7. Based on these results, it can be concluded that Pradhyumna (JGL-17004) and Anjana (JGL-11118) rice varieties belong to lower GI category.

\section{References}

Food and Agricultural organization of the United Nations. FAOSTAT database. 2014. http://fao.org/site/362.

Food and Agricultural Organization of the United Nations (FAO). 2004. Rice is Life, ftp://ftp.fao.org/docrep/fao/008/y5682e/ y5682e00.pdf

Food Fortification Initiative (FFI). 2014. Rice fortification's impact on nutrition. Atlanta, USA: FFI http://www.ffinetwork.org/

Jenkins, D.J., Wolever, T.M., and Taylor, R.H. 1981. Glycemic index of foods: a physiological basis for carbohydrate exchange. American J. Clin. Nutri., 34: 362-366.

Miller, J.B., Pang, E. and Bramall, L. 1992. Rice a high or low glycemic index Food. The American J. Clin. Nutri., 56(6): 10341036.

Snedecor, G.W. and Cochran, W.G. 1983. Statistical methods, Oxford and IBH publishing company, New Delhi.

Umadevi, M., Pushpa, R., Sampathkumar, K.P. and Debjit, B. 2012. Rice - Traditional Medicinal Plant in India. $J$. Pharmacognosy and Phytochem., 1(1): 6-12.

Vijay Kumar. 2015. Rice Production in India During Pre And Post World Trade Organization. Asian J. Multidisciplinary Studies, 3(3): 198-212.

Wolever, J.M.S., Vorster, H.H. and Bjorck, I. 2003. Determination of the glycemic index of foods inter laboratory study. European J. Clin. Nutri., 57: 475-482.

\section{How to cite this article:}

Anitha, R., K. Manorama, W. Jessi Sunitha and Sreedhar, M. 2017. Glycemic Index of Selected Newly Released Rice Varieties of Northern Telangana Region. Int.J.Curr.Microbiol.App.Sci. 6(7): 4300-4304. doi: https://doi.org/10.20546/ijcmas.2017.607.446 